06

\title{
Микроскопия поверхности кремния, имплантированного ионами серебра высокими дозами
}

\author{
(c) В.В. Воробьев, ${ }^{1}$ А.М. Рогов, ${ }^{1}$ Ю.Н. Осин, ${ }^{1}$ В.И. Нуждин, ${ }^{2}$ В.Ф. Валеев, ${ }^{2}$ К.Б. Эйдельман, ${ }^{3}$ Н.Ю. Табачкова, ${ }^{3}$ \\ М.А. Ермаков, ${ }^{4}$ А.Л. Степанов ${ }^{1,2,5}$ \\ ${ }^{1}$ Междисциплинарный центр „Аналитическая микроскопия“ КФУ, \\ 420021 Казань, Россия \\ ${ }^{2}$ Казанский физико-технический институт им. Е.К. Завойского - обособленное структурное подразделение ФИЦ КазНЦ \\ $\mathrm{PAH}$, \\ 420029 Казань, Россия \\ ${ }^{3}$ Национальный исследовательский технологический университет „МИСиС“, \\ 119049 Москва, Россия \\ ${ }^{4}$ Тихоокеанский государственный университет, \\ 680035 Хабаровск, Россия \\ ${ }^{5}$ Казанский национальный исследовательский технологический университет, \\ 420015 Казань, Россия \\ e-mail: slavik.ksu@mail.ru
}

(Поступило в Редакцию 9 апреля 2018 г.)

Проведена низкоэнергетическая имплантация ионами $\mathrm{Ag}^{+}$в монокристаллический $c$-Si c энергией $E=30 \mathrm{keV}$ при дозе облучения от $1.25 \cdot 10^{15}$ до $1.5 \cdot 10^{17} \mathrm{ion} / \mathrm{cm}^{2}$ и плотности тока в ионном пучке от 2 до $15 \mu \mathrm{A} / \mathrm{cm}^{2}$. С помощью сканирующей, просвечивающей электронной и атомно-силовой микроскопии исследована морфология поверхности имплантированных образцов, а также проанализирована их структура методами дифракции отраженных электронов и элементного микроанализа. Показано, что при минимальных используемых дозах облучения $c$-Si происходит аморфизация его приповерхностного слоя. Установлено, что в результате ионной имплантации при превышении пороговой дозы $\sim 3.1 \cdot 10^{15} \mathrm{ion} / \mathrm{cm}^{2}$ в облучаемом слое $\mathrm{Si}$ образуются наночастицы $\mathrm{Ag}$, однородно распределенные по поверхности $\mathrm{Si}$. При дозе более $10^{17} \mathrm{ion} / \mathrm{cm}^{2}$ наблюдается образование пористой структуры $\mathrm{Si}$ при этом, функция распределения наночастицы серебра по размерам становится бимодальной, и наиболее крупные частицы локализованы по стенкам Si-пор.

DOI: 10.21883/JTF.2019.02.47075.145-18

\section{Введение}

Исследования по поиску новых материалов и технологий создания на их основе полупроводниковых приборов, в том числе на $\mathrm{Si}$ наноструктурах, для их использования в промышленной микроэлектронике являются актуальными в настоящее время. В ряде случаев для этого используется пористый $\mathrm{Si}$ (PSi), который на практике в основном получают методом электрохимического травления монокристаллического $c$-Si в растворах плавиковой кислоты $[1,2]$. Однако, помимо химического подхода, также апробируется и технология формирования пористых полупроводниковых слоев с помощью имплантации $\mathrm{Si}$ различными типами ионов в вакууме [3]. PSi представляет интерес для его использования в области микро-, нано- и оптоэлектроники, в частности, для создания солнечных элементов, а также в приложениях биосенсорики [4].

Достаточно хорошо изученным является процесс формирования PSi при высоко дозовой имплантации $\mathrm{Si}$ ионами инертных газов. Растворимость инертных газов в твердых телах относительно мала, поэтому, начиная с некоторых пороговых доз имплантации, в облученном полупроводнике возможно образование наноразмерных пор вследствие заполнения локального объема матери- ала молекулами или пузырьками из ионов имплантируемого газа [3]. Образование пор в $\mathrm{Si}$ наблюдалось при имплантации ионами $\mathrm{H}^{+}[5], \mathrm{He}^{+}[6,7], \mathrm{Ne}^{+}[8], \mathrm{Ar}^{+}[9]$ и $\mathrm{Kr}^{+}[8,10]$. Отличительной особенностью работы [10] является то, что при использовании низкоэнергетической ионной имплантации открытые поры были сформированы не в объеме $\mathrm{Si}$, а на его поверхности. Авторами работы [11] показан способ изготовления пористого слоя в $\mathrm{Si}$ путем имплантации ионами полуметалла $\mathrm{Sb}^{+}$с последующим двухстадийным термическим отжигом, приводящий к последовательному образованию наночастиц $\mathrm{Sb}$, их плавлению и, как следствие, к формированию свободного объема пор в $\mathrm{Si}$.

Кроме того, на практике активно ведутся поиски создания композиционных материалов на основе PSi, coдержащие наночастицы благородных металлов: $\mathrm{Au}$ [12], $\mathrm{Pt}$ [13] и Ag [14]. Задачей данного направления, в частности, является повышение эффективности проявления оптических свойств PSi. Коллективное возбуждение электронов проводимости в металлических наночастицах под действием электромагнитной волны света вызывает резонансное усиление локального поля (поверхностный плазмонный резонанс), что ведет к стимулированию оптических и нелинейно-оптических эффектов в композиционных материалах $[15,16]$. В частности, наличие 
наночастиц $\mathrm{Ag}$ в структуре $\mathrm{Si}$ может способствовать повышению эффективности функционирования солнечных элементов, за счет изменения их поглощательной способности на частотах плазмонного резонанса наночастиц $[17,18]$, а также фотогенерации электронов, возникающих в наночастицах и диффундирующих через барьер Шотки на границе металла и полупроводника [19]. Кроме того, плазмонное поле наночастицы Ag приводит к повышению фотолюминесценции полупроводниковых квантовых точек [20] и усилению комбинационного рассеяния света органических соединений [21], осажденных на PSi.

Ранее для формирования PSi c наночастицами сеpeбpa $(\mathrm{Ag}: \mathrm{PSi})$ было предложено использовать низкоэнергетическую высокодозовую имплантацию $c$ - $\mathrm{Si}$ ионами $\mathrm{Ag}^{+}[22,23]$. Цель настоящей работы заключается в исследовании морфологии и структуры поверхности образцов $\mathrm{Ag}: \mathrm{PSi}$, изготовленных в широком интервале доз имплантации и плотности тока в ионном пучке, при помощи современных методов электронной (сканирующей и просвечивающей) и атомно-силовой микроскопии.

\section{1. Методика эксперимента}

В качестве подложки для иной имплантации использовались монокристаллические пластины $c$-Si c кристаллографической ориентацией (100) p-типа проводимости. Имплантация проводилась ионами $\mathrm{Ag}^{+}$с энергией $E=30 \mathrm{keV}$ при дозе облучения $(D)$ от $6.24 \cdot 10^{13}$ до $1.5 \cdot 10^{17} \mathrm{ion} / \mathrm{cm}^{2}$ и плотности тока в ионном пучке $(J)$ от 2 до $15 \mu \mathrm{A} / \mathrm{cm}^{2}$ на ионном ускорителе ИЛУ-3 при комнатной температуре облучаемой подложки.

Морфология поверхности образцов исследовалась на автоэмиссионном сканирующем электронном микроскопе (СЭM) Merlin (CarlZeiss) при ускоряющем напряжении $\left(U_{\text {acc }}\right)$ нормально падающего на образец электронов зондирующего пучка $5 \mathrm{keV}$, рабочим расстоянии между объективной линзой и поверхностью образца (WD) $2 \mathrm{~mm}$ и токе зонда $\left(I_{\text {prob }}\right) 300 \mathrm{pA}$ в режиме детектирования вторичных электронов с использованием внутрилинзового детектора In-Lens. Элементный анализ регистрировался с помощью энергодисперсионного (ЭДС) спектрометра X-Max (Oxford Instruments) при следующих параметрах работы СЭМ: $U_{\text {acc }}=20 \mathrm{keV}$, $W D=9.6 \mathrm{~mm}$ и $I_{\text {prob }}=600 \mathrm{pA}$, при нормальном падении электронного зонда на образец. При тех же параметpax электронного микроскопа, но при наклоне образца относительно нормали зондирующего луча на угол равный $70^{\circ}$, выполнялись структурные измерения методом дифракции отраженных электронов (ДОЭ) $[24,25]$ с помощью детектора NordLysHKL (Oxford Instruments). Регистрация изображений поперечного скола образцов проводилась на СЭМ Hitachi SU 8230 при $U_{\text {acc }}=3 \mathrm{keV}$, $W D=5 \mathrm{~mm}$ и $I_{\text {prob }}=300 \mathrm{pA}$ в режиме детектирования вторичных электронов. Для этого образец помещался на предметный столик с наклоном $70^{\circ}$ относительно нормали падающего пучка электронов.

Наблюдение топологии поверхности образцов осуществлялось на сканирующем зондовом микроскопе (C3M) Dimension FastScan (Bruker). Измерения проводились в режиме Quantative Nanomechanical Mapping зондами Bruker ScanAsystAirc жесткостью $0.4 \mathrm{~N} / \mathrm{m}$ и paдиусом закругления $\sim 5 \mathrm{~nm}$. Частота сканирования $1 \mathrm{~Hz}$.

Для проведения структурных исследований применялся просвечивающий электронный микроскоп НТ 7700 Excellence (Hitachi) и JEM-2100 (JEOL). Образцы для просвечивающей электронной микроскопии готовили в поперечном сечении. Ионное травление проводили с помощью установки PIPS (Precision Ion Polishing System, Gatan) при ускоряющем напряжении $5 \mathrm{keV}$.

\section{2. Результаты и обсуждение}

\section{1. Зависимость структуры Si от дозы ионной имплантации}

В данном разделе представлены результаты изменения кристаллической структуры на начальной стадии облучении при $D$ от $6.24 \cdot 10^{13}$ до $1.3 \cdot 10^{14} \mathrm{ion} / \mathrm{cm}^{2}$ и фиксированном значении $J=2 \mu \mathrm{A} / \mathrm{cm}^{2}$. На ДОЭ-картине (рис. $1, a)$ от исходного $c$ - $\mathrm{Si}$ видны четкие линии Кикучи. Автоматическая идентификация наблюдаемой ДОЭ-картины с помощью программы Aztec 2.1 показывает кристаллографическую ориентацию (100) кубической сингонии элементарной ячейки $\mathrm{Si}$ с параметрами $a=b=c=0.543 \mathrm{~nm}$ и $\alpha=\beta=\gamma=90^{\circ}$. При имплантации $c-\mathrm{Si}$ подложки ионами $\mathrm{Ag}^{+}$при $D=6.24 \cdot 10^{13} \mathrm{ion} / \mathrm{cm}^{2}$ (рис. $1, b$ ) на ДОЭ-картине наблюдается суперпозиция слабоинтенсивной дифракции от кристаллической подложки $c$-Si (в виде слегка размытых полос Кикучи) и от аморфизованного приповерхностного слоя $a-\mathrm{Si}$ (в виде дуффузных колец). Такая суперпозиция возникает из-за того, что в приповерхностном имплантированном слое присутствуют области аморфного кремния, образованные в результате внедрения отдельных ионов $\mathrm{Ag}^{+}$. В случае $D=1.3 \cdot 10^{14} \mathrm{ion} / \mathrm{cm}^{2}$ и более на ДОЭ-картине (рис. $\left.1, c\right)$ присутствуют только диффузные кольца $a-\mathrm{Si}$, что соответствует полностью аморфизованному слою $\mathrm{Si}$. Из ДОЭ-измерений можно заключить о постепенной частичной аморфизации приповерхностной области $\mathrm{Si}$ с ростом дозы имплантации, а при ее достижении величины порядка $1.3 \cdot 10^{14} \mathrm{ion} / \mathrm{cm}^{2}$ происходит полная аморфизация имплантированного слоя толщиной $\sim 30 \mathrm{~nm}[26]$. Приведенные результаты хорошо согласуются с данными спектральной эллипсометрии [26], в которых было показано, что при $D=6.24 \cdot 10^{13} \mathrm{ion} / \mathrm{cm}^{2}$ процентное содержание $a$-Si в имплантированном слое составляет $\sim 90 \%$, а при $D=1.3 \cdot 10^{14} \mathrm{ion} / \mathrm{cm}^{2}-100 \%$.

Следует отметить, что морфология поверхности образцов $\mathrm{Si}$, имплантированных при $D$ от $6.24 \cdot 10^{13}$ до $1.3 \cdot 10^{14} \mathrm{ion} / \mathrm{cm}^{2}$ и $J=2 \mu \mathrm{A} / \mathrm{cm}^{2}$, наблюдаемая на 
$a$

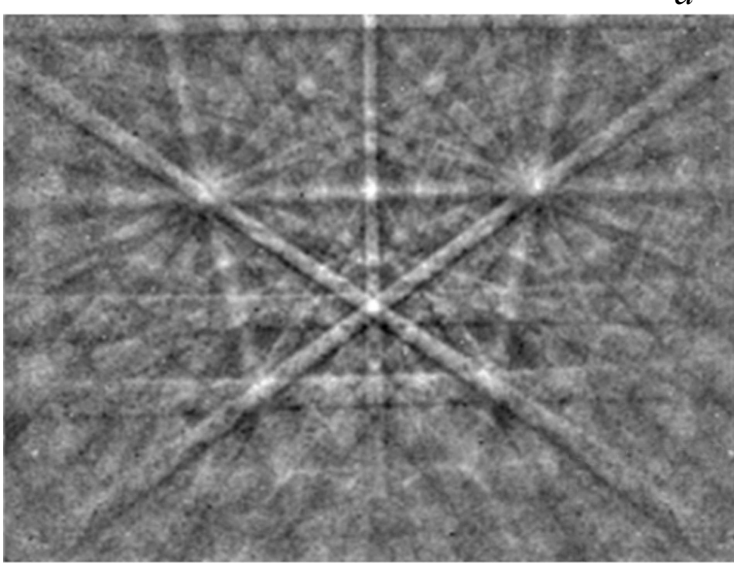

$b$

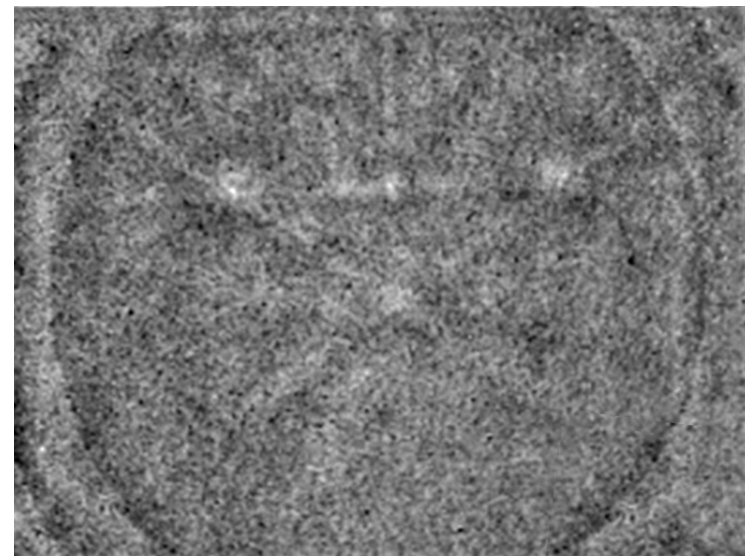

$c$

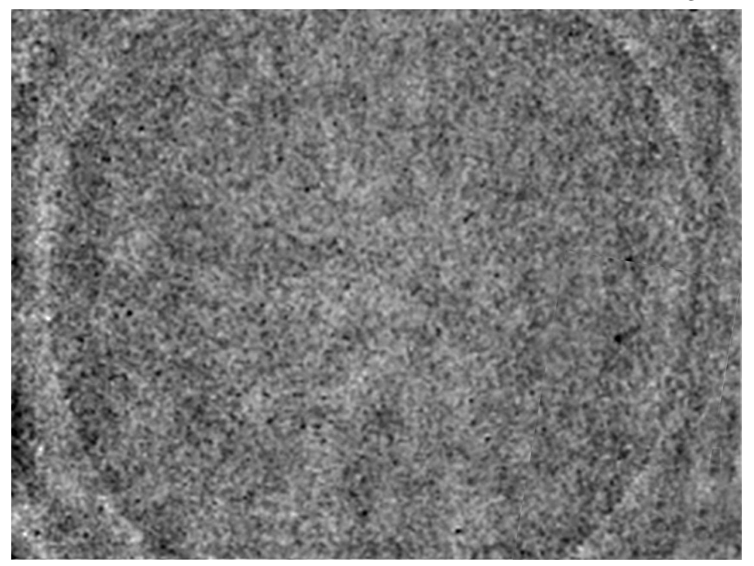

Рис. 1. ДОЭ-картины, от исходного $c$ - $\mathrm{Si}(a)$ и $\mathrm{Si}$, имплантированного ионами $\mathrm{Ag}^{+}$при $D:(b) 6.24 \cdot 10^{13}$ и $(c) 1.3 \cdot 10^{14}$ ion $/ \mathrm{cm}^{2}$.

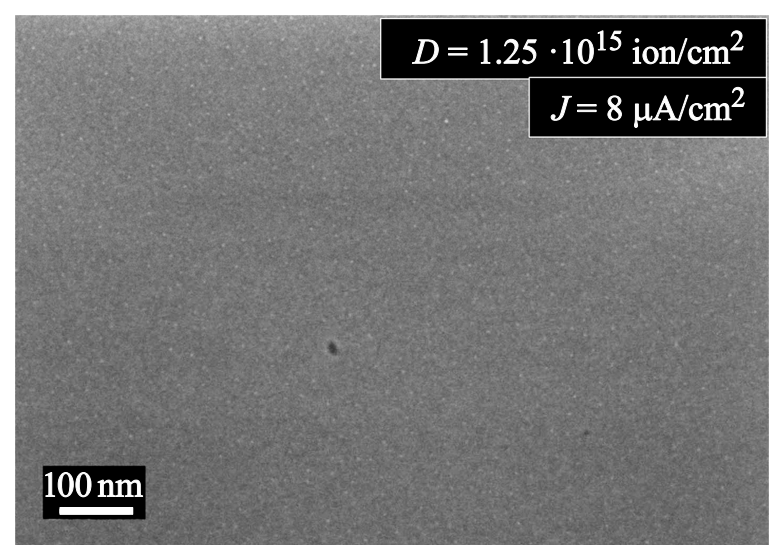

Рис. 2. СЭМ-изображение поверхности $\mathrm{Si}$, имплантированного ионами $\mathrm{Ag}^{+}$при $D=1.25 \cdot 10^{15} \mathrm{ion} / \mathrm{cm}^{2}, E=30 \mathrm{keV}$ и $J=8 \mu \mathrm{A} / \mathrm{cm}^{2}$.

СЭМ-изображениях, не изменяется, остается гладкой и ровной, сравнимой с исходной подложкой, как это показано на примере для $\mathrm{Si}$, имплантированного при низкой $D=1.25 \cdot 10^{15} \mathrm{ion} / \mathrm{cm}^{2}$ (рис. 2 ).

\section{2. Синтез наночастиц серебра при ионной имплантации Si}

Как было отмечено во введении, ранее в работах $[22,23]$ была показана принципиальная возможность синтеза наночастиц серебра при низкоэнергетической высокодозовой $\left(>10^{17} \mathrm{ion} / \mathrm{cm}^{2}\right)$ имплантации $c$-Si. Для определения пороговой величины $D$ ионами $\mathrm{Ag}^{+}$в $\mathrm{Si}$ для энергии $30 \mathrm{keV}$, при которой происходит зарождение металлических наночастиц, были проведены СЭМ наблюдения образцов, сформированных для различных значений $D$ от $1.25 \cdot 10^{15}$ до $1.5 \cdot 10^{17} \mathrm{ion} / \mathrm{cm}^{2}$, при постоянных параметрах ионной имплантации $E=30 \mathrm{keV}$ и $J=8 \mu \mathrm{A} / \mathrm{cm}^{2}$.

Как следует из СЭМ-наблюдений (рис. 1,a) при облучении с наименьшей $D=1.25 \cdot 10^{15} \mathrm{ion} / \mathrm{cm}^{2}$ на имплантированной поверхности $\mathrm{Si}$ какие-либо морфологические неоднородности не появляются, и она остается ровной и гладкой, как у исходной подложки. При этом на ЭДС-спектре данного образца дополнительно к сигналу подложки Si присутствуют пики, расположенные между 2.5 и $3.5 \mathrm{keV}$, которые соответствуют характеристическим линиям серебра. По расчетным данным толщина имплантированного приповерхностного 

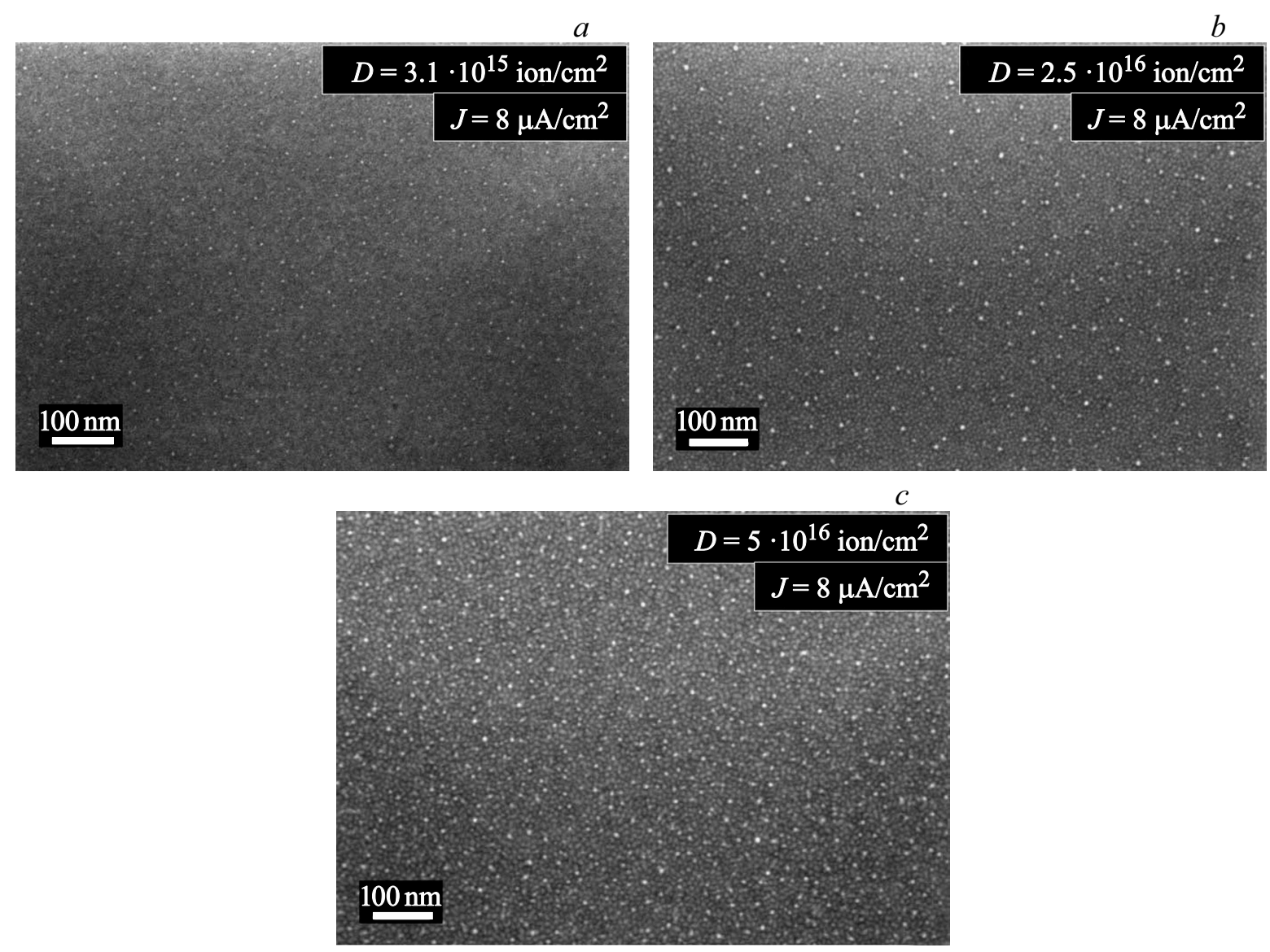

Рис. 3. СЭМ-изображения поверхности $\mathrm{Si}$, имплантированного ионами $\mathrm{Ag}^{+}$при $J=8 \mu \mathrm{A} / \mathrm{cm}^{2}$ и различных значениях $D: a-$ $3.1 \cdot 10^{15}, b-2.5 \cdot 10^{16}$ и $c-2.5 \cdot 10^{16} \mathrm{ion} / \mathrm{cm}^{2}$.

Гранулометрические характеристики ионно-синтезированных наночастиц $\mathrm{Ag}$ в приповерхностном слое $\mathrm{Si}$

\begin{tabular}{c|c|c|c}
\hline $\begin{array}{c}\text { Доза } \\
\text { имплантации, } \\
\text { ion } / \mathrm{cm}^{2}\end{array}$ & $\begin{array}{c}\text { Средний диаметр } \\
\text { наночастиц, } \\
\mathrm{nm}\end{array}$ & $\begin{array}{c}\text { Плотность } \\
\text { наночастиц на } \\
\text { единицу площади, } \\
\mathrm{N} / \mathrm{cm}^{2}\end{array}$ & $\begin{array}{c}\text { Среднее } \\
\text { расстояние } \\
\text { между } \\
\text { частицами, } \\
\mathrm{nm}\end{array}$ \\
\hline $3.1 \cdot 10^{15}$ & 2 & $25 \cdot 10^{9}$ & 37 \\
$2.5 \cdot 10^{16}$ & 3 & $39 \cdot 10^{9}$ & 32 \\
$5 \cdot 10^{16}$ & 5 & $60 \cdot 10^{9}$ & 28
\end{tabular}

слоя $\mathrm{Si}$ ионами $\mathrm{Ag}^{+}$составляет порядка $40 \mathrm{~nm}$ [22], что заведомо меньше глубины зондирования образца электронами $(\sim 1 \mu \mathrm{m})$ при ЭДС. Из этого можно заключить, что при ЭДС-измерении анализируется все вещество серебра, имплантированное в Si. Отсутствие видимых морфологических изменений на поверхности образца при ионном облучении $\mathrm{Si}$, вплоть до $D=1.25 \cdot 10^{15} \mathrm{ion} / \mathrm{cm}^{2}$, указывает на то, что серебро в приповерхностном слое $\mathrm{Si}$ находится в атомарном состоянии.
Для $\mathrm{Si}$, имплантированного ионами $\mathrm{Ag}^{+}$при более высокой дозе $D=3.1 \cdot 10^{15} \mathrm{ion} / \mathrm{cm}^{2}$, как видно на СЭМ-изображении (рис. 3,a), в отличие от меньшей дозы (рис. 2) присутствуют светлые яркие круглые пятна со средним диаметром $\sim 2 \mathrm{~nm}$, однородно распределенные на сером фоне поверхности образца. Заметим при этом, что при СЭМ-наблюдениях изображение формируется за счет столкновения электронов с поверхностью анализируемого материала и их отражения при некоторых потерях энергии с регистрацией на детекторе [25]. При этом цветовая тональность на СЭМ изображении определяется в первую очередь плотностью вещества на поверхности исследуемого материала. Известно также, что Ag не образует химических соединений c Si. Поэтому, очевидно полагать, что образец, показанный на рис. 3, $a$ демонстрирует наличие в его приповерхностном слое две различающиеся по плотности и цветовой тональности фазы, а именно серого фона для менее плотного $\mathrm{Si}$ и яркие светлые пятна, которые следует относить к синтезированным наночастицам $\mathrm{Ag}$. Отсутствие посторонних химических элементов в данном образце, как было отмечено, подтверждается ЭДС-анализом. Образование наночастиц $\mathrm{Ag}$ при данной величине $D$ объясняется накоплением атомов $\mathrm{Ag}$ в 

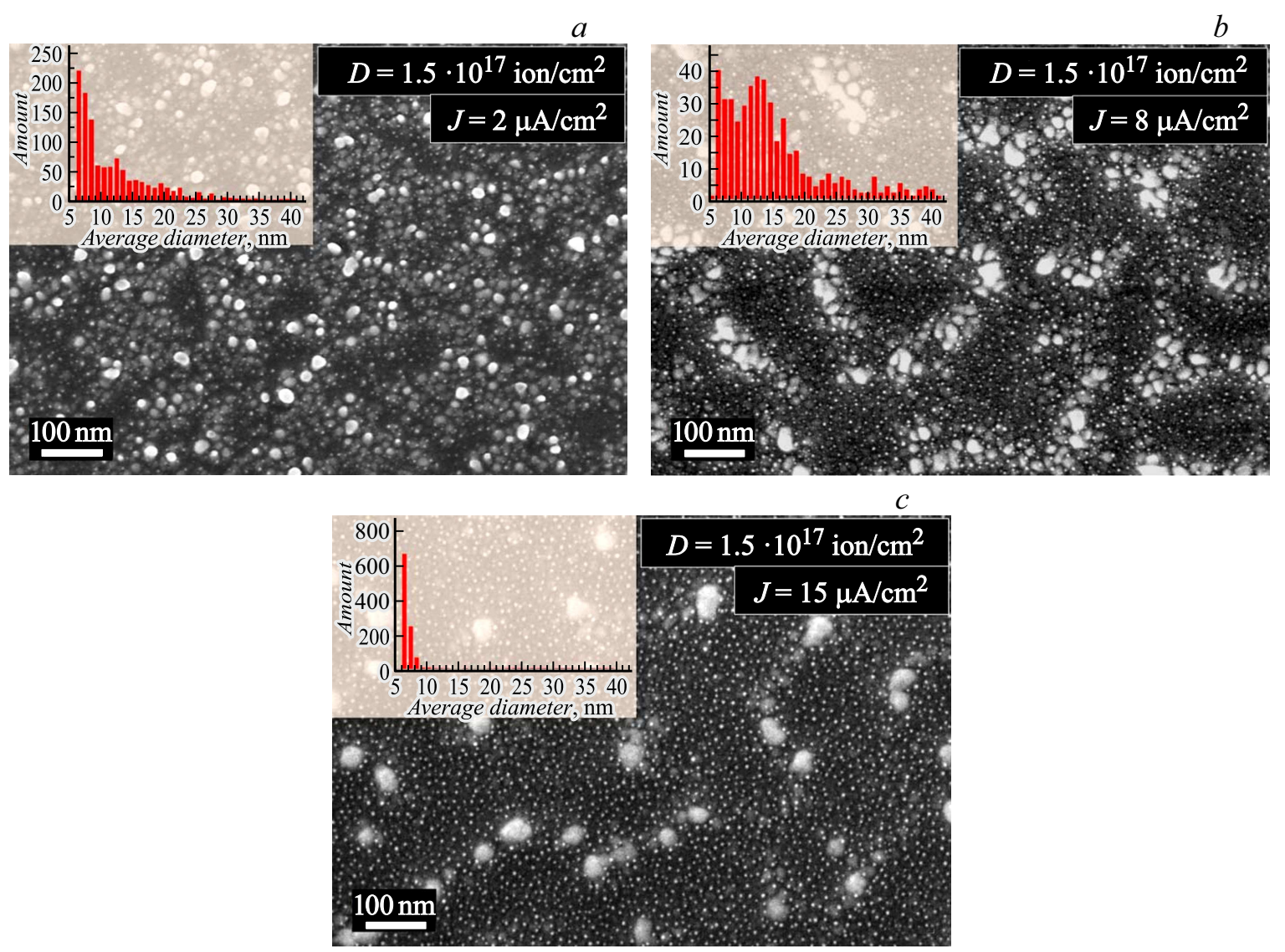

Рис. 4. СЭМ-изображения поверхности $\mathrm{Si}$, имплантированного ионами $\mathrm{Ag}^{+}$при $D=1.5 \cdot 10^{17}$ ion/ $\mathrm{cm}^{2}$ и различных значениях $J$ : $a-2, b-8$ и $c-15 \mu \mathrm{A} / \mathrm{cm}^{2}$.

количествах, превышающих его предел растворимости в $\mathrm{Si}>10^{16} \mathrm{~cm}^{-3}$ [27]. При возникновении пресыщения атомы $\mathrm{Ag}$, диффундируя по приповерхностному объему $\mathrm{Si}$, сегрегируют в металлические наночастицы аналогично тому, как это происходит в пересыщенных растворах, а также в стеклах и полимерах при их высокодозовой ионной имплантации [16]. Оцененное по СЭМ-изображению (рис. 3, a) среднее расстояние между наночастицами составляет $237 \mathrm{~nm}$, а их плотность по поверхности образца равна $25 \cdot 10^{9} \mathrm{~N} / \mathrm{cm}^{2}$, где $N$ количество частиц (см. таблицу). Таким образом, $D$, равную $\sim 3.1 \cdot 10^{15} \mathrm{ion} / \mathrm{cm}^{2}$, можно считай критической дозой (при $E=30 \mathrm{keV}$ и $J=8 \mu \mathrm{A} / \mathrm{cm}^{2}$ ) при которой зарождаются и формируются устойчивые от случайного разрушения наночастицы Ag.

Для образцов, имплантированных при более высоких дозах $D=2.5 \cdot 10^{16} \mathrm{ion} / \mathrm{cm}^{2}$ и $D=5 \cdot 10^{16} \mathrm{ion} / \mathrm{cm}^{2}$, на СЭМ изображениях на рис. $3, b$ и $c$ соответственно также наблюдаются светлые пятна наночастиц серебра на сером фоне Si. При этом с ростом $D$ размер наночастиц (3 и $5 \mathrm{~nm})$ и их плотность $\left(39 \cdot 10^{9}\right.$ и $60 \cdot 10^{9} \mathrm{~N} / \mathrm{cm}^{2}$ ) увеличивается, а среднее расстояние между ними уменьшается 32 и $28 \mathrm{~nm}$. Таким образом, очевидно, что с ростом ионной $D$ поступающие в $\mathrm{Si}$ в бо́льшем количестве ионы $\mathrm{Ag}$ диффундируют к уже сформировавшимся наночастицам $\mathrm{Ag}$ (стокам), приводя к увеличению размеров частиц и повышению их поверхностной плотности, как это отражено в таблице.

\section{3. Распределение наночастиц $\mathrm{Ag}$ по поверхности имплантированного $\mathrm{Si}$ в зависимости от плотности тока в ионном пучке}

На рис. 4 приведены СЭМ-изображения, на которых показано, как изменяется поверхность имплантированного $c$-Si при различных $J=2,8$ и $15 \mu \mathrm{A} / \mathrm{cm}^{2}$ при фиксированной величине $D=1.5 \cdot 10^{17} \mathrm{ion} / \mathrm{cm}^{2}$ и $E=30 \mathrm{keV}$. Яркие светлые пятна на темном фоне $\mathrm{Si}$-подложки, как было описано выше, отображают ионно-синтезированные наночастицы Ag. Эти наночастицы Ag условно можно разделить по величине на две группы (бимодальное распределение): мелкие и крупные. Для каждого образца на вставках показаны гистограммы распределения наночастиц по размерам. Характерная особенность гистограмм для $J=2$ и $15 \mu \mathrm{A} / \mathrm{cm}^{2}$ (рис. 4, a, c) заключается в наличии доминирующей фракции наночастиц с размерами $\sim 7 \mathrm{~nm}$, которые равномерно распределены по площади всех образцов. Концентрация наночастиц 


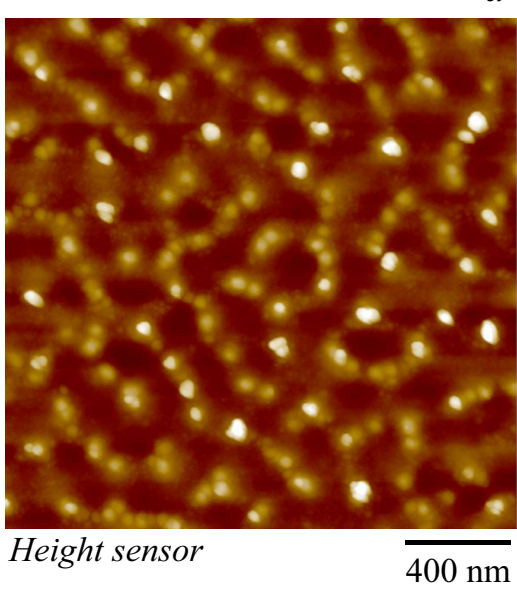

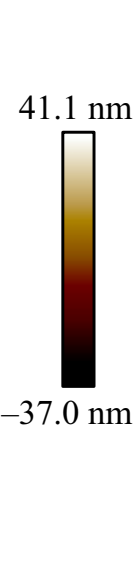

$b$

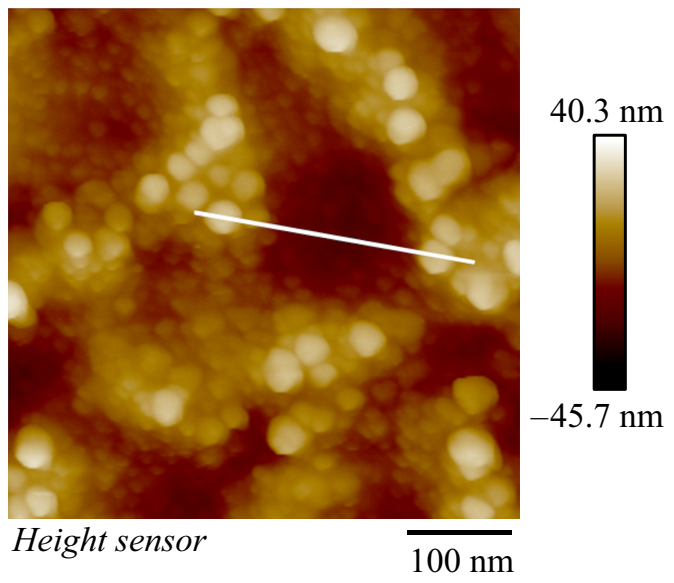

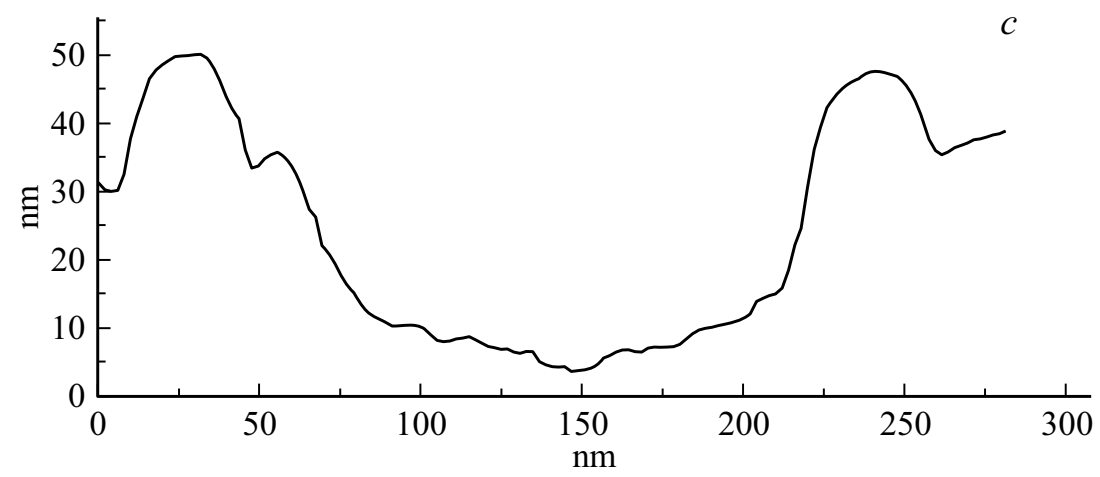

Рис. 5. СЗМ-изображение $c$-Si, имплантированного ионами $\mathrm{Ag}^{+}$при $D=1.5 \cdot 10^{17} \mathrm{ion} / \mathrm{cm}^{2}$ и $J=8 \mu \mathrm{A} / \mathrm{cm}^{2}$.

данного размера на единицу площади выше для образца, полученного при более высоком значении $J$, тогда как разброс по размерам (ширина гистограммы на половине ее высоты) меньше. Для случая $J=8 \mu \mathrm{A} / \mathrm{cm}^{2}$ (рис. $4, b$ ) мелкие наночастицы имеют средний диаметр $10 \mathrm{~nm}$. Для $J=2 \mu \mathrm{A} / \mathrm{cm}^{2}$ также наблюдается относительно равномерное распределение по поверхности крупных наночастиц $\mathrm{Ag} \sim 30 \mathrm{~nm}$ (рис. $4, a$ ). В случае $J=8 \mu \mathrm{A} / \mathrm{cm}^{2}$ (рис. $4, b$ ) крупные наночастицы $\sim 40 \mathrm{~nm}$ распределяются по окружностям со средним диаметром $250 \mathrm{~nm}$. Как будет показано далее, окружности на поверхности имплантированного кремния образованы открытыми порами, по периметру которых и концентрируются крупные наночастицы. Для $J=15 \mu \mathrm{A} / \mathrm{cm}^{2}$ на СЭМ-изображении (рис. 4,c) наблюдаются более крупные наночастицы $\sim 60 \mathrm{~nm}$ и их расположение уже не составляет замкнутых окружностей, а в какой-то мере напоминает цепочки.

\section{4. Морфология поверхности $\mathrm{Si}$, имплантированного ионами $\mathrm{Ag}$ при высоких дозах}

С целью оценки морфологических изменений поверхности $\mathrm{Si}$ при образовании наночастиц $\mathrm{Ag}$ высокодозовой имплантацией ионами $\mathrm{Ag}^{+}$были проведены дополни- тельные СЗМ-, СЭМ- и ПЭМ-исследования для образца, облученного при $D=1.5 \cdot 10^{17} \mathrm{ion} / \mathrm{cm}^{2}$ и $J=8 \mu \mathrm{A} / \mathrm{cm}^{2}$. На СЗМ-изображениях данного образца (рис. $5, a, b$ ) видно, что облученная поверхность образца оказывается пористой. Профиль сечения поверхности, измеренный вдоль направления по отрезку, как показано на рис. $5, b$, представлен на рис. 5, $c$. Согласно количественным замерам, глубина рассмотренной открытой поры составляет $\sim 45 \mathrm{~nm}$, а ее диаметр $\sim 250 \mathrm{~nm}$.

На рис. 6, а схематически представлена область сьемки СЭМ-изображения под углом $\mathrm{Si}$, имплантированного при $D=1.5 \cdot 10^{17} \mathrm{ion} / \mathrm{cm}^{2}$ и $J=8 \mu \mathrm{A} / \mathrm{cm}^{2}$. СЭМ-изображение поперечного скола в режиме детектирования вторичных электронов приведено на рис. $6, b$. Темная область на нижней половине СЭМ-изображения образца (рис. 6, $b$ ) соответствует торцевой стороне подложки исходного $c$-Si. На верхней части рисунка показана поверхность $\mathrm{Ag}$ : $\mathrm{PSi}$ под углом. На данной поверхности наблюдается морфологическая особенность образца, образованная сформированными при имплантации открытыми порами $\mathrm{Si}$, состоящая из относительно неглубоких ямок (пор). При этом, как будет показано далее, по периметру стенок пор расположены крупные наночастицы $\mathrm{Ag} \sim 40 \mathrm{~nm}$. При этом мелкие наночастицы $(\sim 7 \mathrm{~nm})$ распределены равномерно по всей площади, 


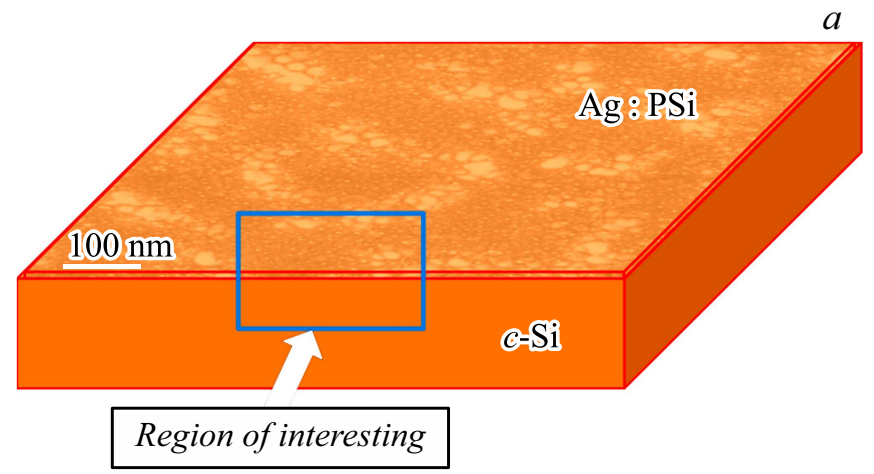

$b$
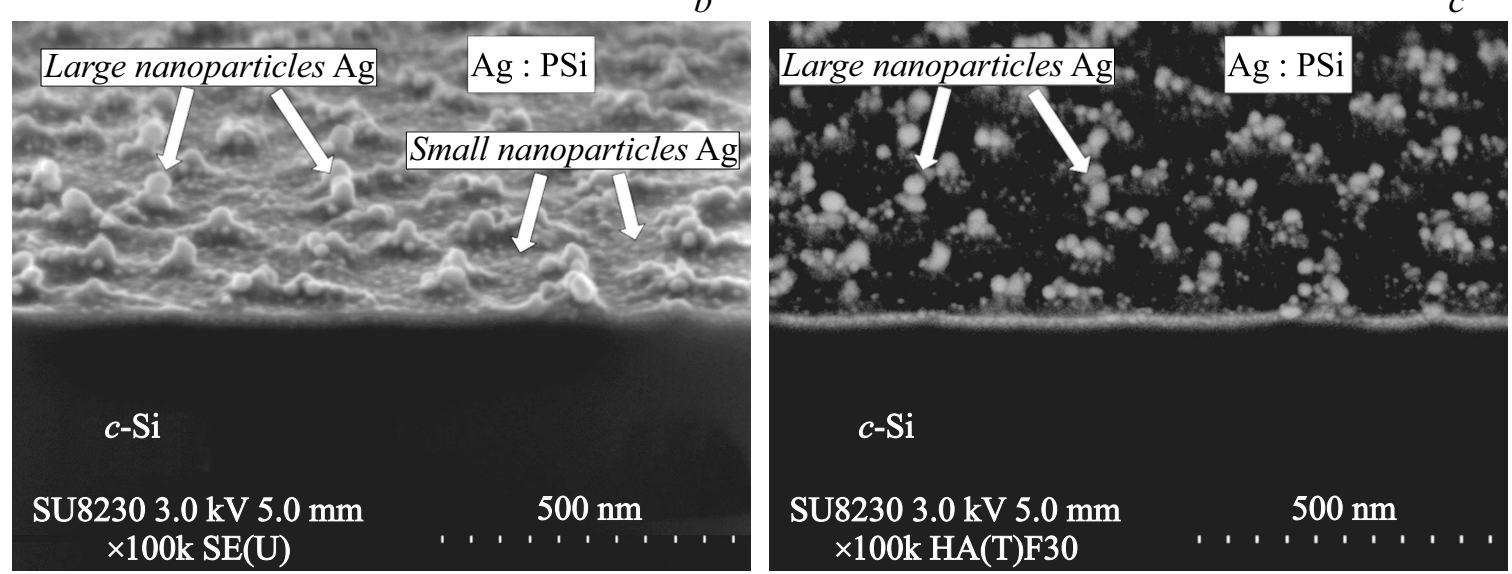

Рис. 6. Схема регистрации микрофотографий $(a)$. СЭМ-изображение поперечного скола $\mathrm{Ag}$ : PSi имплантированного ионами $\mathrm{Ag}^{+}$при $D=1.5 \cdot 10^{17} \mathrm{ion} / \mathrm{cm}^{2}$ и $J=8 \mu \mathrm{A} / \mathrm{cm}^{2}$ в режиме детектирования вторичных электронов $(b)$ и отраженных электронов с применением энергетического фильтра $(c)$.

$a$
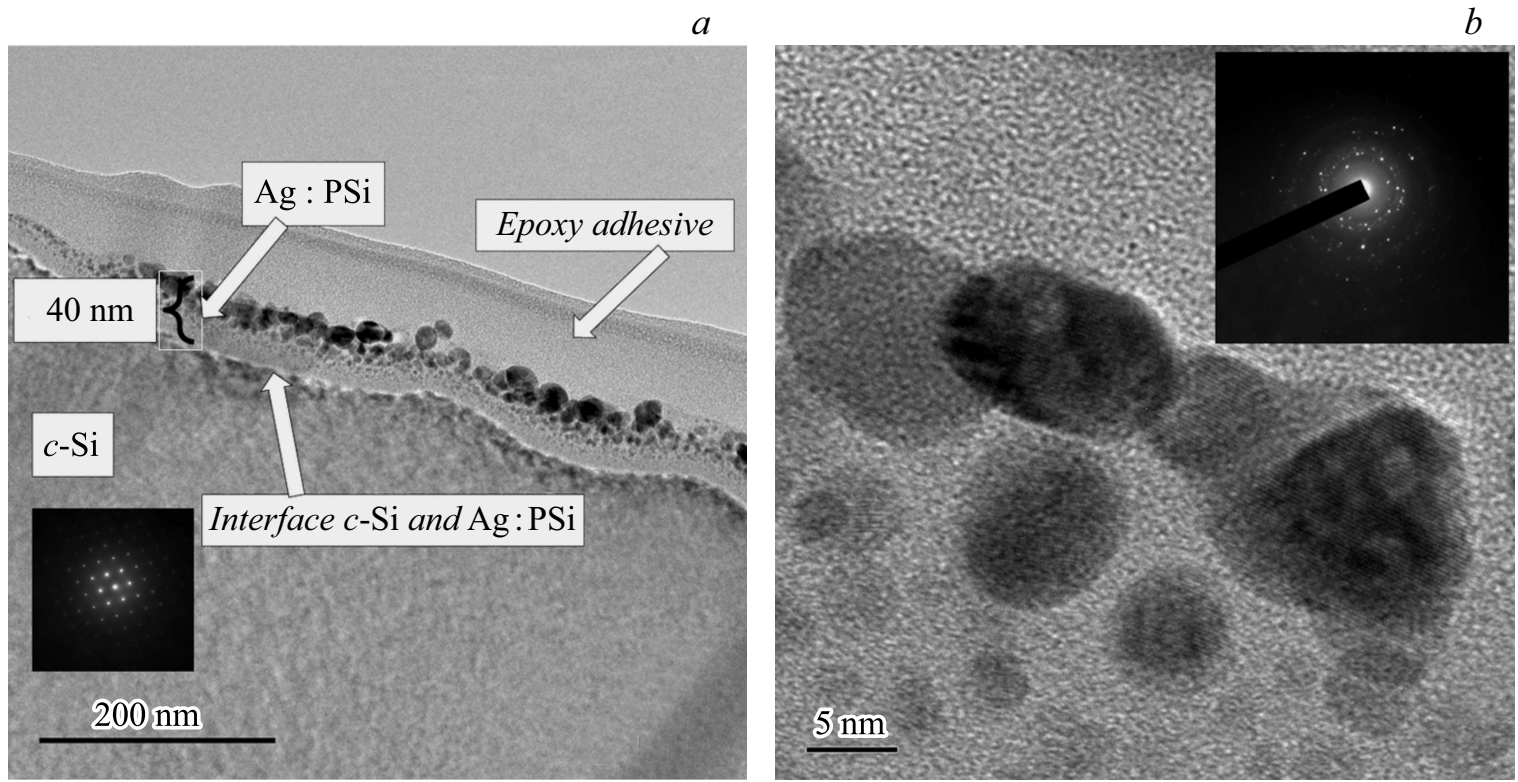

Рис. 7. ПЭМ-изображения: (a) поперечного среза (cross-section) приповерхностного слоя $\mathrm{Ag}$ : PSi, имплантированного ионами $\mathrm{Ag}^{+}$при $D=1.5 \cdot 10^{17} \mathrm{ion} / \mathrm{cm}^{2}$ и $J=8 \mu \mathrm{A} / \mathrm{cm}^{2}$ (НТ 7700 Excellence) и увеличенное изображение слоя $\mathrm{Ag}: \mathrm{PSi}(b)$, на вставке микродифракция от наночастиц $\mathrm{Ag}$ (JEM-2100). 
что согласуется с СЭМ-изображением, полученном на микроскопе в геометрии „plan-view“ на рис. 5.

На рис. 6, с показана та же область образца, как на рис. $6, b$, но зарегистрированная в режиме детектирования отраженных электронов с применением энергетического фильтра, обеспечивающего отсев электронов малой энергии от фазы $\mathrm{Si}$ при регистрации на детекторе только высокоэнергетических электронов от тяжелых атомов Ag. Так как в соответствии с ЭДС-анализом в образце присутствуют только атомы $\mathrm{Ag} \mathrm{и} \mathrm{Si}$, это изображение на рис. 6,c подтверждает формирование наночастиц Ag на поверхности. Следует отметить, что из-за меньшего разрешения, по сравнению с детектором вторичных электронов, на рис. 6, $c$ хорошо видны только крупные наночастицы Ag.

На рис. 7 приведены ПЭМ-изображения поперечного сечения $\mathrm{Si}$, имплантированного ионами $\mathrm{Ag}^{+}$при $D=1.5 \cdot 10^{17} \mathrm{ion} / \mathrm{cm}^{2}$ и $J=8 \mu \mathrm{A} / \mathrm{cm}^{2}$. Нижняя часть изображения (рис. 7,a) соответствует $c$-Si подложки, кристаллическая структура которой представлена на вставке того же рисунка. Выше над необлученной подложкой $c$-Si располагается имплантированный слой $\mathrm{Ag}$ : PSi толщиной порядка $40 \mathrm{~nm}$ [23]. Между подложкой $c$-Si и Ag:PSi наблюдается тонкий, толщиной $\sim 2 \mathrm{~nm}$ слой интерфейса, являющийся переходным между кристаллической и аморфной фазами $\mathrm{Si}$. В слое $\mathrm{Ag}: \mathrm{PSi}$ вдоль всего среза на верхней его стороне (поверхности образца) наблюдаются ионно-синтезированные наночастицы Ag. Также на поверхности образца, над слоем $\mathrm{Ag}$ :PSi присутствуют остатки эпоксидного клея, который использовался при пробоподготовке срезов. На рис. 7, $b$ показано увеличенное ПЭМ изображение имплантированного приповерхностного участка образца с наночастицами Ag. На выбранном локальном участке размеры частиц варьируются от 5 до $20 \mathrm{~nm}$. На вставке рис. 7, $b$ показана микродифракция от Ag-наночастиц, которая соответствует гранецентрированной кристаллической фазе Ag-наночастиц с разной ориентацией.

\section{Выводы}

Таким образом, в работе показано, что при использовании низкоэнергетической имплантации $c$-Si ионами $\mathrm{Ag}^{+}$с энергией $E=30 \mathrm{keV}$ при $D$ от $1.25 \cdot 10^{15}$ до $1.5 \cdot 10^{17} \mathrm{ion} / \mathrm{cm}^{2}$ и $J$ от 2 до $15 \mu \mathrm{A} / \mathrm{cm}^{2}$ установлено следующее. При значении $D=1.3 \cdot 10^{14} \mathrm{ion} / \mathrm{cm}^{2}$ приповерхностная область $\mathrm{Si}$ полностью аморфизируется. Начиная с $D=3.1 \cdot 10^{15} \mathrm{ion} / \mathrm{cm}^{2}$ в области $a$-Si слоя происходит зарождение однородных по размеру наночастиц Ag. При дальнейшем росте $D$ зафиксировано повышение количества наночастиц, размеры которых увеличиваются от 5 до $50 \mathrm{~nm}$. При $D=1.5 \cdot 10^{17} \mathrm{ion} / \mathrm{cm}^{2}$ на поверхности имплантированного $\mathrm{Si}$ наблюдается формирование открытых пор глубиной $\sim 50-60 \mathrm{~nm}$, диаметром $\sim 200-250 \mathrm{~nm}$ и толщиной стенок $\sim 60-80 \mathrm{~nm}$. При этом размерное распределение наночастиц Ag становит- ся бимодальным, состоящим из двух фракций: мелкие наночастицы $(5-10 \mathrm{~nm})$, располагающиеся равномерно по всему образцу, и крупные $(40-50 \mathrm{~nm})$, лежащие на стенках пор. Таким образом, совместное использование взаимодополняющих методов микроскопии (СЭМ, СЗМ и ПЭМ) и их вариаций позволяет подробно охарактеризовать сложные поверхностные структуры, что и было продемонстрировано на примере композиционного материала $\mathrm{Ag}$ : PSi, сформированного ионной имплантацией.

Работа выполнена при финансовой поддержке Российского научного фонда (проект № 17-12-01176).

\section{Список литературы}

[1] Panarin A.Yu., Terekhov S.N., Kholostov K.I., Bondarenko V.P. // Appl. Surf. Sci. 2010. Vol. 256. P. 6969-6976.

[2] Yen-Chen Maggie Liou, Jiann-Yeu Chen, Jyisy Yanga. // App. Spectr. 2014. Vol. 68. N 2. P. $172-178$.

[3] Козловский В.В., Козлов В.А., Ломасов В.Н. // ФТП. 2000. Vol. 34. P. 129-147.

[4] Ищенко А.А., Фетисов Г.В., Асланов Л.А. Нанокремний: свойства, получение, применение, методы исследования и контроля. М.: Физматлит, 2011. С. 573.

[5] Cerofolini G.F., Meda L., Balboni R., Corni F., Frabboni S., Ottaviani G., Tonini R., Anderle M., Canteri R. // Phys. Rev. 1992. Vol. 46. P. 2061-2073.

[6] Stein H.J., Myers S.M., Follstaedt D.M. // J. Appl. Phys. 1993. Vol. 73. P. 2755-2764.

[7] Реутов В.Ф., Сохацкий А.С. // ЖТФ. 2003. Вып. 73. C. $73-78$.

[8] Wittmer M., Roth J., Revesz P., Mayer J.M. // J. Appl. Phys. 1978. Vol. 49. P. 5207-2512.

[9] Revesz P., Wittmer M., Roth J., Mayer J.M. // J. Appl. Phys. 1978. Vol. 49. P. 5199-5206.

[10] Галяутдинов М.Ф., Курбатова Н.В., Буйнова Э.Ю., Штырков Е.И., Бухараев А.А. // ФТП. 1997. Вып. 31. C. $1130-1134$.

[11] Садовский П.К., Челядинский А.Р., Оджаев В.Б., Тарасик М.И., Туриевич А.С., Васильев Ю.Б. // ФТТ. 2013. Т. 55. Вып. 6. С. $1071-1073$.

[12] Amran T.S., Hashim M.R., Al-Obaidi N.K., Yazid H., Adnan R. // Nanoscale Res. Lett. 2013. Vol. 8. P. 35-41.

[13] Wang M., Wang X., Ghoshal S. // Micro \& Nano Lett. 2013. Vol. 8. P. 465-469.

[14] Wang Y., Liu Y.P., Liang H.L., Mei Z.X., Du X.L. // Phys. Chem. Chem. Phys. 2013. Vol. 12. P. 2345-2350.

[15] Kreibig U., Vollmer M. Optical properties of metal clusters. Berlin: Springer, 1995. P. 468.

[16] Степанов А.Л. Фотонные среды с наночастицами, синтезированные ионной имплантацией, Саарбрюккен, Lambert Acad. Publ. 2014. 353 c.

[17] Atwater H.A., Polman A. // Natur. Mater. 2010. P. 205-213.

[18] Степанов А.Л., Воробьев В.В., Нуждин В.И., Валеев В.Ф., Осин Ю.Н. // Журн. прикладной спектроскопии. 2017. T. 84. № 5. C. 726-730.

[19] Knight M.W., Sobhani H., Nordlander P., Halas N.J. // Science. Vol. 332. P. 702-704.

[20] Галяметдинов Ю.Г., Шамилов Р.Р., Степанов А.Л. // Известия АН. Сер. хим. 2016. № 11. Р. 2773-2775. 
[21] Воробьев В.В., Рогов А.М., Осин Ю.Н., Брандт Н.Н., Нужсдин В.И., Валеев В.Ф., Степанов А.Л. // Опт. и спектр. 2018. в печати. Т. 124. Вып. 5. С. 617-622.

[22] Stepanov A.L., Trifonov A.A., Osin Y.N., Valeev V.F., Nuzhdin V.I. // Optoelectr. Adv. Mater. Rapid Comm. 2016. Vol. 7. N 9-10. P. 692-697.

[23] Степанов А.Л., Осин Ю.Н., Трифонов А.А., Валеев В.Ф., Нужсдин В.И. // Российские нанотехнологии. 2014. Т. 9. № 3-4. С. 53-56.

[24] Швари, А., Кумар М., Адамс Б. Метод дифракции отраженных электронов в материаловедении. М.: Техносфера, 2014. C. 560.

[25] Растровая электронная микроскопия для нанотехнологий. Методы и применение / Под ред. У. Жу, Ж.Л. Уанга. Пер. с англ. М.: Бином, 2006. 599 с.

[26] Базаров В.В., Нужсдин В.И., Валеев В.Ф., Воробьев В.В., Осин Ю.Н., Степанов А.Л. Журн. прикладной спектроскопии. 2016. Т. 83. № 1. С. 55-59.

[27] Глазов В.М., Земсков В.С. Физико-химические основы легирования полупроводников. М.: Наука, 1967. 372 с. 